\title{
Maritime network dynamics before and after international events
}

\author{
FANG Zhixiang ${ }^{1,3},{ }^{*}$ YU Hongchu ${ }^{1}$, LU Feng ${ }^{2}$, FENG Mingxiang ${ }^{1}$, HUANG Meng ${ }^{1}$ \\ 1. State Key Laboratory of Information Engineering in Surveying, Mapping and Remote Sensing, Wuhan Uni- \\ versity, Wuhan 430079, China; \\ 2. State Key Laboratory of Resources and Environmental Information System, Institute of Geographic Sciences \\ and Natural Resources Research, CAS, Beijing 100101, China; \\ 3. Collaborative Innovation Center of Geospatial Technology, Wuhan 430079, China
}

\begin{abstract}
Investigating the influence of international events on global maritime networks is a challenging task that must comprehensively incorporate geographical, political, and maritime sciences. Understanding global maritime network dynamics is an initial and critical step in this investigation. This study proposes an automatic identification system (AIS)-based approach to understanding maritime network dynamics before and after international events. In this approach, a spatiotemporal modeling method is introduced to measure the similarity in shipping trends before and after international events. Then, a spatiotemporal analytic framework is proposed to understand the maritime network dynamics by grouping similar situation, and assessing possible indirect effects within a network. Finally, three case studies of international events, military conflict, lifted economic sanctions, and government elections, were used to investigate the observed network dynamics possibly affected by international events. The results indicate that container, tanker, and bulk shipping between India and its connected countries all declined more than $69 \%$ after military conflicts between India and Pakistan in August 2015. Tanker shipping between Iran and the United Arab Emirates increased 51\% after economic sanctions on Iran were lifted. Container shipping between Sri Lanka and Singapore, Malaysia, and India increased more than $74 \%$ after the general election in Sri Lanka. These investigations demonstrate the feasibility of the proposed approach in assessing the possible effects of international events on maritime network dynamics.
\end{abstract}

Keywords: global maritime network; fluctuation dynamics; international events; spatiotemporal similarity

\section{Introduction}

Understanding network dynamics is a challenge in physics, geography, economics, and

Received: 2017-10-17 Accepted: 2017-12-20

Foundation: Key Project of the Chinese Academy of Sciences, No.ZDRW-ZS-2016-6-3; The National Key Research and Development Program of China, No.2017YFB0503802; National Natural Science Foundation of China, No.40971233, No.41771473; LIESMARS Special Research Funding

Author: Fang Zhixiang (1977-), Professor, specializing in transport geography, human behavior modeling, space-time GIS and intelligent navigation. E-mail: zxfang@whu.edu.cn

"Corresponding author: Yu Hongchu (1990-), PhD Candidate, specializing in spatiotemporal data analysis in maritime transportation. E-mail: hongshuxifan8140@163.com 
network sciences. The maritime network, one of the most important networks in international trade, acts as a fundamental transportation mode for strategic goods and materials critical to economic development worldwide. A better understanding of maritime network dynamics would help evaluate the potential implications of international events; this would be an asset to policy makers designing effective national strategies, including for investing, developing regional relationships, optimizing the global maritime logistics network, and even improving national competition.

Previous researches on maritime networks focused on structure, flows, maritime transportation efficiency, and maritime safety (see Table 1). The few studies that have researched dynamic properties of maritime networks include the changing hierarchies of ports (Ducruet and Notteboom, 2012), multiplex network dynamics of maritime flows (Ducruet, 2017), and co-evolutionary dynamics of ports and cities in the global maritime network (Ducruet, 2016). These efforts help us understand the hierarchical structure, regional characteristics, and several dynamics properties in regional or global maritime networks. In addition, some studies have explained international events from the perspectives of international relations (King and Zeng, 2001), economics, and finance (MacKinlay, 1997). Some work has evaluated the influence of these international events, for example, Schinas and Westarp (2017) assessed the impact of the Maritime Silk Road on existing maritime liner services. However, a large gap remains in our understanding of maritime network dynamics effected by international events between countries, such as military conflicts, economic sanctions, and government elections.

Table 1 Summary of research on maritime networks

\begin{tabular}{|c|c|}
\hline Research category & Research contents \\
\hline Structure and dynamics & $\begin{array}{l}\text { Spatial structure (Xu et al., 2015); regional dynamics (Ducruet and Notteboom 2012; } \\
\text { Ducruet, 2017; Yu et al., 2017); time dynamics (Ducruet, 2016); spatial heterogeneity } \\
\text { (Liu et al., 2017; Li et al., 2016); reachability (Li et al., 2014b), and local strength and } \\
\text { global weakness (Ducruet et al., 2009). }\end{array}$ \\
\hline Network and flows & $\begin{array}{l}\text { Network diversity and maritime flows (Ducruet, 2013; Dinwoodie et al., 2013); statis- } \\
\text { tical properties, including distribution extent, correlations, weight distribution, strength } \\
\text { distribution, average shortest path length, line length distribution, and centrality meas- } \\
\text { ures (Hu and Zhu, 2009; Fugazza, 2017); centrality and vulnerability (Laxe et al., } \\
\text { 2012; Viljoen and Joubert, 2016; Wu et al., 2017; Wang et al., 2016); connectivity and } \\
\text { complexity (Jiang et al., 2015; Tian et al., 2007; Liu and Hu et al., 2017); inequality } \\
\text { (Xu et al., 2015a); and evaluations of robustness (Peng et al., 2017). }\end{array}$ \\
\hline $\begin{array}{l}\text { Maritime transport } \\
\text { and efficiency }\end{array}$ & $\begin{array}{l}\text { Direct port-to-port service, hub, and spoke networks (Fremont, 2007; Wang and Wang, } \\
\text { 2011); maritime economics (Stopford, 2009); logistics (Rodrigue and Browne, 2002; } \\
\text { Song and Lee, 2009; Davarzani et al., 2016); transportation (Guerrero and Rodrigue, } \\
\text { 2014; Gagatsi et al., 2017); transport network design (Angeloudis et al., 2015; Karsten } \\
\text { et al., 2017) and their network efficiency (Song et al., 2005; Tai and Hwang, 2005; } \\
\text { Zeng and Yang, 2002; Fahmiasari and Parikesit, 2017); intermediacy (Rodrigue, 2017); } \\
\text { maritime transport chain choice (Talley and Ng, 2013; Lam and Yam, 2011) and inter- } \\
\text { actions (Knappett et al., 2008); and oligopolistic and competitive carrier behavior (Lee } \\
\text { et al., 2012). }\end{array}$ \\
\hline Maritime safety & $\begin{array}{l}\text { Risk (Akhtar and Utne, 2014; Li et al., 2014a); safety (Hänninen et al., 2014); and ma- } \\
\text { ritime search and rescue operations (Bezgodov and Esin, 2014a) }\end{array}$ \\
\hline
\end{tabular}

This study proposes a spatiotemporal analysis approach to understand maritime network dynamics before and after international events. A global tracking dataset of ships collected 
through the automatic identification system (AIS) (Høye et al., 2008) is used to demonstrate the feasibility of the proposed approach. The AIS is designed to exchange information between ships or ship and shore facilities, including vessel real-time location, speed, and course information. The AIS data can be used to derive the time-varying global maritime network automatically by recovering ship trajectories. The proposed approach is summarized as follows:

Spatiotemporal modeling method is proposed to measure the similarity in shipping trend curves before and after international events. The curves for any link in the maritime network are divided into crests and troughs to find the same trend between two lines. Similarity is measured by integrating the total time of parallel trends and minimum crossing area between curves. This method identifies similar dynamics in terms of voyage number or tonnage between any two maritime network nodes.

A spatiotemporal analytic framework is used to model the maritime network dynamics. The maritime network dynamics are derived from AIS data to determine the potential effects of international events based on measured similarity, for example, the affected link within the network and possible indirect effect on dynamics.

Three international event scenarios, i.e., military conflict, and government election, were used to investigate the possible effect of international events on maritime network dynamics. The results demonstrate that the proposed framework is feasible and useful to help evaluate this effect.

The remainder of this paper is organized as follows. Section 2 reviews the literature describing the spatiotemporal dynamics of maritime networks. Section 3 describes the proposed spatiotemporal approach for understanding maritime network dynamics before and after international events. Section 4 introduces the case studies and discusses the possible effects of these international events.

\section{Literature review}

The spatiotemporal dynamics of maritime networks are reviewed from the perspectives of flow and spatial structure, regional dynamics, time and behavior dynamics.

In terms of flow and spatial structure, various researches have described the hub-and-spoke structure in the Atlantic container shipping system (Ducruet et al., 2010), maritime cluster organization (Viederyte, 2013), coastal maritime clusters (Doloreux et al., 2016), regional maritime connectivity (Mohamed-Chérif and Ducruet, 2016), multilayer dynamics of complex spatial networks in global maritime flows (Ducruet, 2017), transshipment hub flows and gateway flows (Ducruet and Notteboom, 2012), maritime oil freight flows (Dinwoodie et al., 2013), seasonal characteristics of maritime traffic (Campana et al., 2017), and collaborative maritime transportation (Silva, 2013). These studies provide context for the structure and flow characteristics of maritime networks. However, the characteristics of maritime network dynamics affected by international events remain an open research topic in this area.

In terms of regional dynamics, Guerrero and Rodrigue (2014) suggested that there were five main successive waves of containerization in the maritime network and indicated a shift from advanced economies to developing economies in some regions, i.e., East Asia and 
South America. van Leeuwen (2015) discussed the polycentric governance system dynamics in the European Union. Xu et al. (2015) investigated the evolution of regional inequality in the global shipping network. These dynamics analyses could reveal the changing regional role in maritime networks. However, few studies have focused on identifying regional dynamics effects in maritime networks in response to international events.

In terms of time dynamics, a recent book Maritime Network Spatial Structures and Time Dynamics edited by Ducruet (2016) comprehensively reviewed the geo-history of maritime networks, past maritime network modeling, maritime network monitoring, time considerations in complex maritime networks, and progress in the regional development of maritime studies, and co-evolutionary dynamics of port and cities in the global maritime network. These prior studies have provided some time characteristics of maritime network dynamics. However, a time-series analysis approach is required to understand the time-dependent effects of local changes on links in regional maritime networks to reveal the effects on nodes or countries in regional or global maritime networks. This approach would enable logical decisions for international strategies to improve economic development and national relationships.

Finally, recent works have focused on behavior dynamics in the maritime network, such as the oligopolistic and competitive behavior of carriers in maritime freight transportation networks (Lee et al., 2012), port choice behavior (Kim, 2014), cooperative carrier behavior (Lee et al., 2014), and anomaly behavior (Lei, 2016). Castaldo et al. (2015) used Bayesian techniques to focus on micro-level dynamics and the effect of micro behaviors on dynamics in the global maritime network.

In summary, investigating the effect of international events on the spatiotemporal dynamics of maritime network remains a relatively unexplored research topic. This study proposes a spatiotemporal analysis approach to understand maritime network dynamics before and after international events. We think that this work will be helpful for national strategies that address the effects of international events on maritime network dynamics.

\section{Methodology}

\subsection{Overview of the proposed analytic framework}

Figure 1 provides an overview of the proposed analytic framework to understand maritime network dynamics before and after international events. This framework integrates port location data and AIS trajectory data to build a global or regional maritime network, which can be derived from origins and destinations between countries. Second, the time an international event occurs is used to separate the AIS trajectory dataset and construct the before-event and after-event networks. The spatiotemporal trend curves for each link in the before- and after-event networks are generated to identify similar spatiotemporal changes between countries. Third, this framework constructs a subnetwork with similar spatiotemporal changes by grouping countries with similar changes. Finally, this framework evaluates the possible effects of international events on the maritime network by comparing the possible affected countries and their connected countries. Detailed descriptions of these steps are given in the following subsections. 


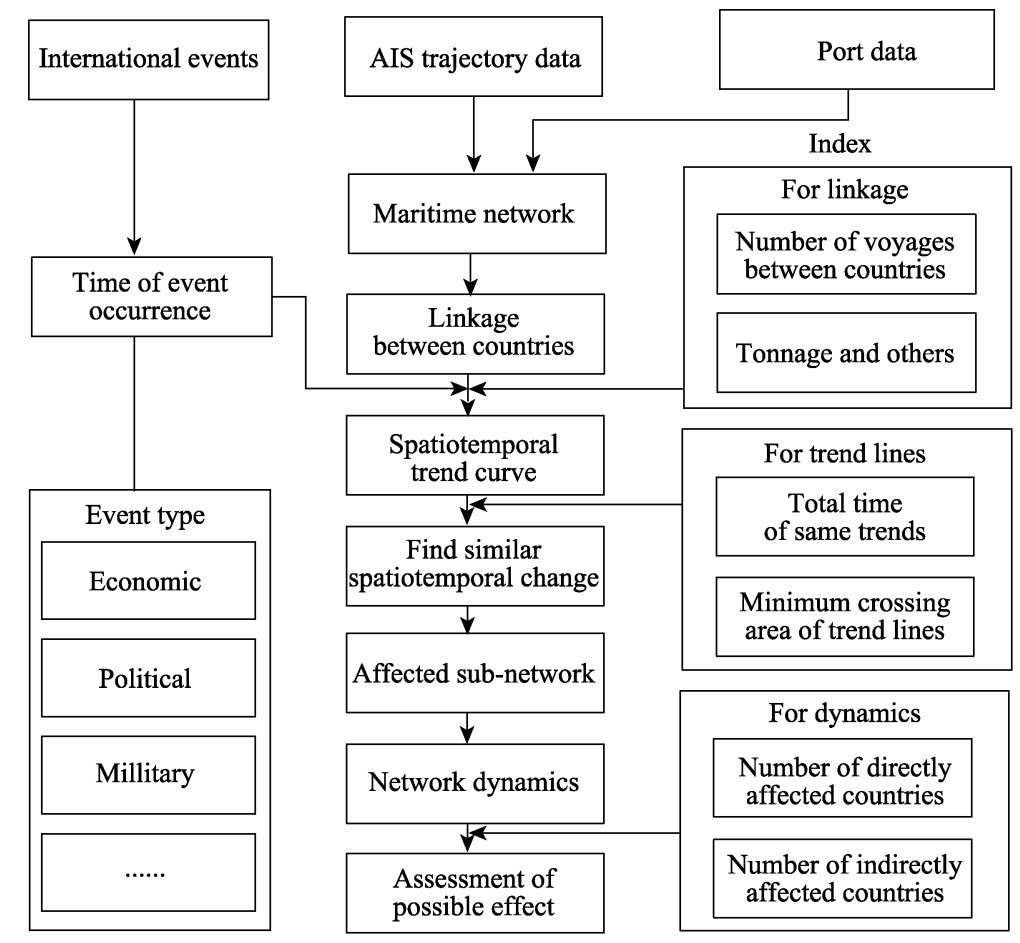

Figure 1 Proposed analytic framework

\subsection{Building the maritime network}

The time-varying maritime network was constructed using AIS data. The raw AIS data content was introduced by Fiorini et al. (2016), which includes vessel identification (MMSI, Maritime Mobile Service Identity), navigation status (at anchor, under way using engines, or not under command), rate of turn, ground speed, position accuracy, longitude and latitude, ground course, true heading, and time stamps. The AIS transmitter sends additional information, such as IMO (International Maritime Organization) ship identification number, international radio call sign, vessel name, type of ship/cargo, ship dimensions, type of positioning system, ship draught, destination, and estimated time of arrival at destination via the AIS system. Among them, the longitude and latitude information in each raw data entry represents the vessel location, as the AIS points for ships 1 and 2 plotted in Figure 2a. Therefore, the time-series locations of this vessel between ports could be viewed as the vessel trajectory. For example, there are some trajectories between ports $\mathrm{AB}, \mathrm{BC}, \mathrm{DC}, \mathrm{DE}$, and EA for ship 1, and between ports $\mathrm{AC}, \mathrm{CB}, \mathrm{BE}, \mathrm{BD}, \mathrm{DE}$, and $\mathrm{AE}$ for ship 2. Therefore, a time-varying maritime network between ports is created by connecting each port pair in trajectories as links within any time period unit, such as day, month, season, year, or multiple years. Each link includes attributes, such as voyage number and tonnage, where the voyage number represents the total number of times vessels voyage between two linked ports. For example, numbers 1 or 2 is plotted near the links in Figure $2 \mathrm{~b}$. The next step is to combine ports in a country to construct country-based maritime networks. For example, Figure $2 \mathrm{c}$ shows the maritime network between countries. Here, the time-varying maritime network between countries is constructed using the month time unit because this study explores the network 
dynamics before and after international events within several years.

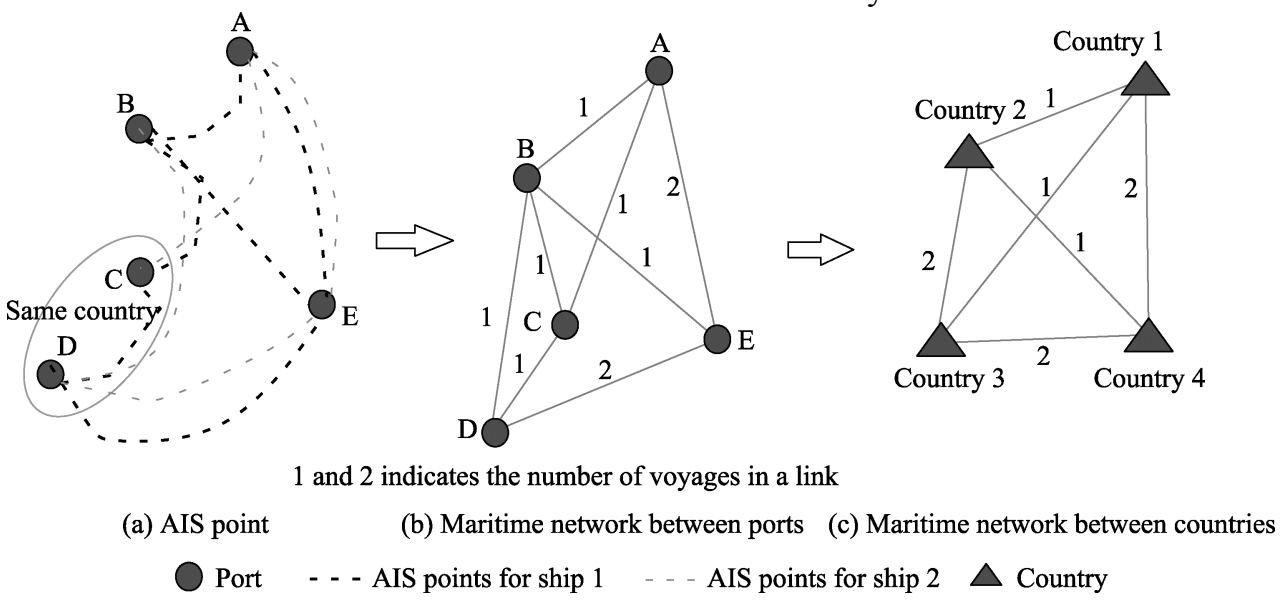

Figure 2 Constructing maritime network from AIS data

\subsection{Measuring trend similarities between links}

Before measuring trend similarities between links in a maritime network, trend curves need to be fitted. There are two popular methods for fitting curves: the multivariate locally polynomial fitting approach (LOESS) (Cleveland et al., 1988) and autoregressive moving average (ARMA) models (Box et al., 1976). LOESS is a very popular local regression method with favorable statistical and computational properties. It combines the simplicity of traditional linear regression and flexibility of non-linear regression. The primary advantage is that determining a predefined regression function is not required for any data, but the drawback is the intensive computation. The ARMA model is a widely used forecast approach for fitting time-series data using discrete-time filtering methods, which provides a parsimonious description of a (weakly) stationary stochastic process in terms of two polynomials, one for the autoregression and another for the moving average. The ARMA model is parameter-dependent, and adjusting parameters for any unknown maritime network is challenging. Therefore, this study uses the LOESS model to generate fitting curves for the time-series link attributes; for example, curve parts $a$ and $b$ are trend curves before and after Event $\mathrm{A}$ in Figure 3a. If a link has $m$ statistical variants $\left\{v_{1}, v_{z}, \ldots, v_{m}\right\}$, it creates $m$ corresponding trend curves $\left\{c_{1}, c_{z}, \ldots, c_{m}\right\}$.

The similarity of the trends for variant $v_{j}$ (i.e., voyage number or tonnage) is defined by two indicators: the total time for the same trends and the minimum crossing area between curves. Figure $3 \mathrm{~b}$ illustrates the segment divisions for curves 1 and 2 based on curve crest or trough. Each segment monotonically increases, decreases, or remains unchanged in trend. Therefore, the total time of the same trends $(t)$ for $v_{j}$ (see Figure $3 \mathrm{~b}$ ) is defined as:

$$
t^{j}=\Delta t_{1}+\Delta t_{2}+\Delta t_{3}+\cdots+\Delta t_{i}+\Delta t_{i+1}+\Delta t_{i+2}+\cdots+\Delta t_{n}=\sum_{i \leqslant n} \Delta t_{i}
$$

where $\Delta t_{i}$ is the time span when the two curves have the same trend, monotonically increasing, decreasing, or unchanging.

The second indicator is the minimum crossing area between curves. Figure $3 \mathrm{c}$ shows the crossing area between curves, which is calculated as: 


$$
\Delta A_{1,2}^{j}=\int_{t=t_{0}}^{t=t_{1}}\left(f\left(c_{1}^{j}, t\right)-f\left(c_{2}^{j}, t\right)\right) d t=\sum_{t=t_{0}}^{t=t_{1}}\left\{f\left(c_{1}^{j}, t\right)-f\left(c_{2}^{j}, t\right)\right\} \Delta t
$$

where $f\left(c_{1}^{j}, t\right)$ and $f\left(c_{2}^{j}, t\right)$ are the functions for curves $c_{1}^{j}$ and $c_{2}^{j}$, respectively. The values $t_{0}$ and $t_{1}$ are the start and end times in the analysis task.

Here, one curve (see curve IR in Figure 3c) is moved to find the minimum crossing area. Determining the moving distance for a curve is critical for finding this minimum crossing area. In this study, a binary search strategy is used to solve the problem. The "average line" in Figure $3 \mathrm{c}$ represents the line where $\mathrm{y}$ is the average value of all points in the curve. Curve IR is moved by aligning the average lines of the two curves. Once moved, the curves can be used to find the upper and lower limits for each. The maximum moving distance for curve IR is $h$. Then, equation (2) is used to calculate the crossing area between curves IN and IR while moving curve IR distance $\Delta h$ from the average line. The binary search strategy first calculates the crossing areas for $\Delta h=0, h / 2, h$. Then, if the minimum area is located at $\Delta h=0$, the next search will use the parameters $\Delta h=0, h / 4, h / 2$. If the minimal area is located at $\Delta h=0$, $h / 2$, the next search will use the parameters $\Delta h=0, h / 4, h / 2,3 h / 4$. If the minimum area is located at $\Delta h=h$, the next search will use the parameters $\Delta h=h / 2,3 h / 4, h$. This search process is

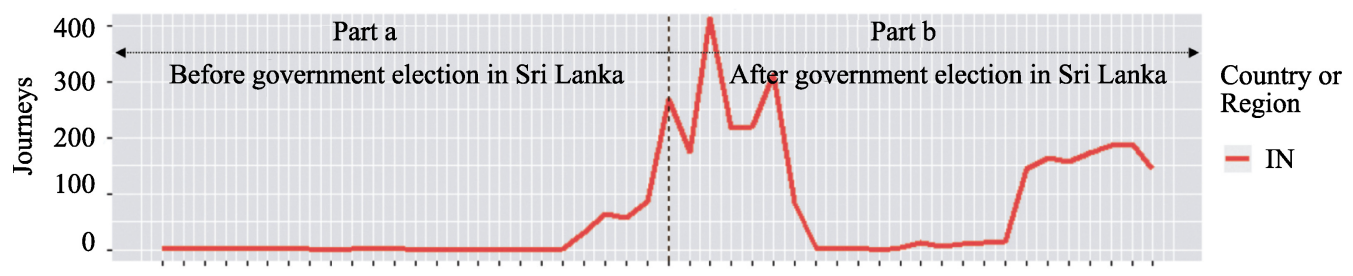

Event C-Government election in Sri Lanka

(a) Trend line of container shipping between India and Sri Lanka before and after event C

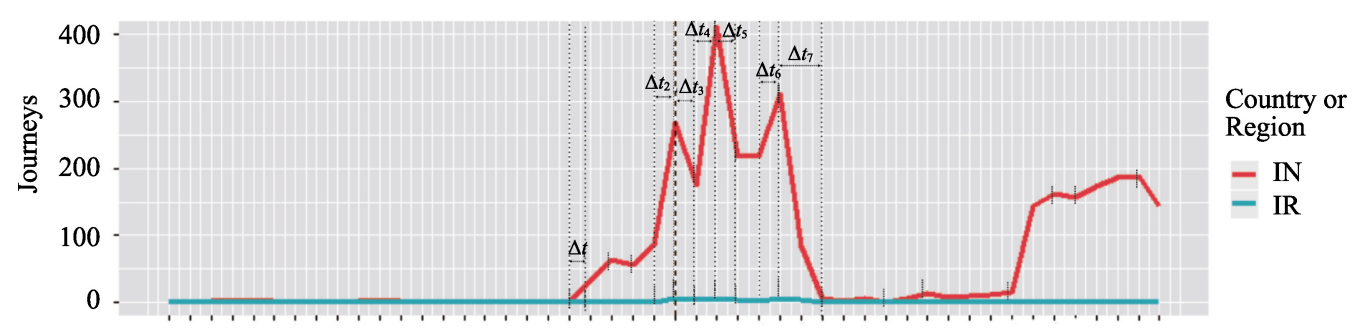

Event C-Government election in Sri Lanka

(b) Trend curves with separated increasing and decreasing process where $\Delta t_{i}$ means the time period that lines $\mathrm{AE}$ and $\mathrm{IN}$ have the same trend

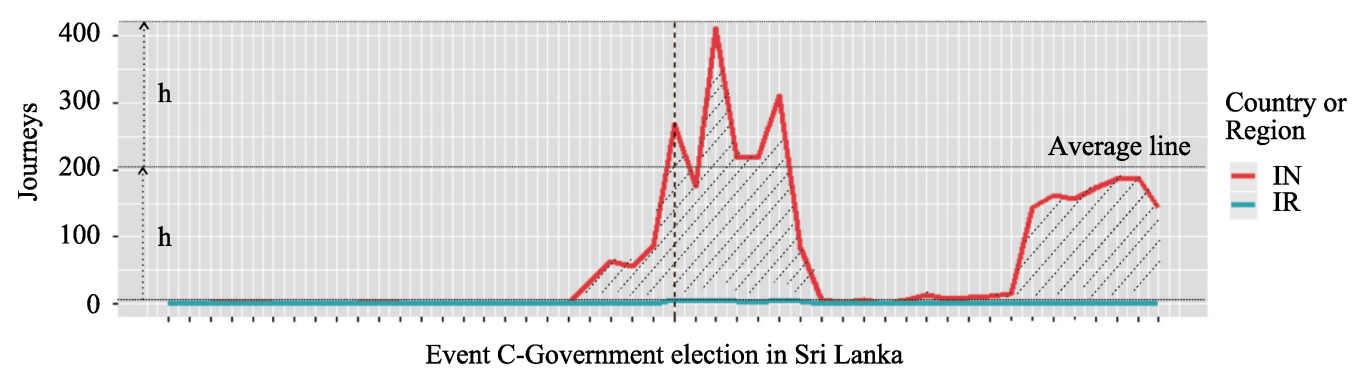

(c) Minimal crossing area

Figure 3 Indicators used to find similar spatiotemporal trend curves 
repeated when the search meets the requirement of a predefined minimum value of variant $y$. Such a strategy finds the minimum crossing area by comparing the minimum values from the average line to the upper and lower limits.

The similarity index for variable $v_{j}$ in two links $l_{1}, l_{2}$ is defined based on the following rule: if the trend curves for variable $v_{j}$ in these two links has longer $t^{j}$ and smaller $\Delta A_{1,2}^{j}$, they are more similar. To reflect the effect of $t^{j}$ and $\Delta A_{1,2}^{j}$ on a single similarity index, we normalize their values to $(0,1)$ and the similarity of two links is measured as follows:

$$
\begin{gathered}
\operatorname{sim}\left(v_{j}, l_{1}, l_{2}\right)=\frac{N\left(t^{j}\right)}{N\left(\Delta A_{1,2}^{j}\right)} \\
N\left(t^{j}\right)=\frac{t^{j}}{t_{1}-t_{0}} \\
N\left(\Delta A_{1,2}^{j}\right)=\frac{\Delta A_{1,2}^{j}}{\max \left(\Delta A_{1,2}^{j}\right)}
\end{gathered}
$$

where $N\left(t^{j}\right)$ is the normalized value of $t^{j}, N\left(\Delta A_{1,2}^{j}\right)$ is the normalized value of $\Delta A_{1,2}^{j}$, and $\operatorname{sim}\left(v_{j}, l_{1}, l_{2}\right)$ represents the similarity of time-varying changes in variant $v_{j}$ in links $l_{1}$, and $l_{2}$.

\subsection{Grouping links by similar dynamics in maritime network links}

Every link in the maritime network has spatiotemporal dynamics observable in its event curve. When exploring the effect of international Event A in a country, e.g., Sri Lanka (Figure 4a), we divide the links connected with Sri Lanka into two parts, those with and without clear trend changes. The division rules are explained in Figure $4 \mathrm{c}$, where $d_{a}$ and $d_{b}$ are the maximum change distance in the trend curve before and after Event $\mathrm{A}$ and $v 1, v 2, v 3, v 4, v 5$, $v 6, v 7, v 8, v 9, v 10$, and $v 11$ are the change speeds for the curve segment divided by the crest or trough. We use $d_{a}$ and $d_{b}, \max \{v 1, v 2, v 3\}$, and $\max \{v 4, v 5, v 6, v 7, v 8, v 9, v 10, v 11\}$ to find the links with differing trends (see Group 2 in Figure 4e). The other links without clear trend changes are included in Group 1 (Figure 4d).

After grouping these links, the well-known K-means (Lloyd, 1982; MacQueen, 1967; Borgwardt et al., 2017) method was used to classify the links in Group 2 to identify highly similar patterns in this group. This approach uses the similarity of time-varying changes in variant $v_{j}$ in these links as the clustering distance. The drawbacks of the K-means algorithm are the difficulty in finding the K-value and high dependency on initial partitions of the dataset (Arora1 et al., 2016). A recently developed efficient K-means clustering filtering algorithm (Kumar and Reddy, 2017) was used to solve this problem; it uses density-based initial cluster centers, which improves the performance of the K-means filtering by locating seed points at dense areas in the dataset. The dense areas are identified by representing the data points in a kd-tree. This approach can overcome the drawbacks of the well-known $\mathrm{K}$-means when used to classify links in maritime networks. As a result, in this study, classified clusters were generated with different similar trend changes, and each cluster could be used to assess the possible effect of international events, as described in the next subsection. 


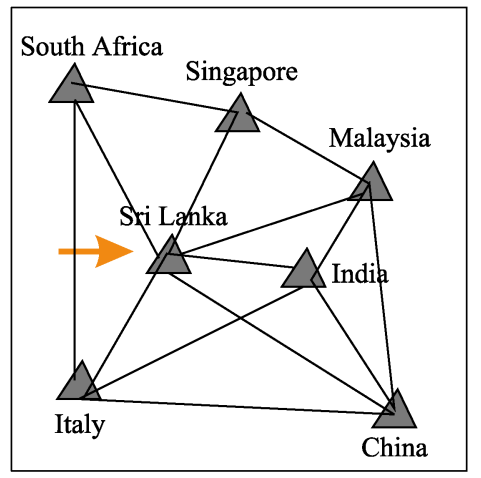

(a) Maritime network:

Event C-government election in Sri Lanka

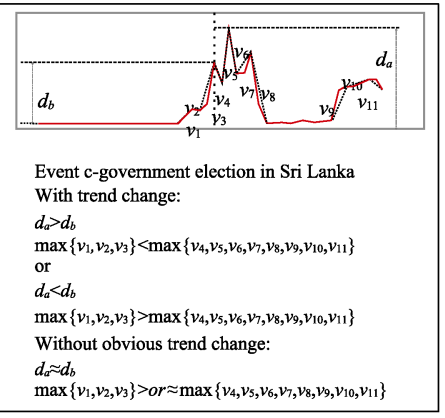

(c) Classification rules

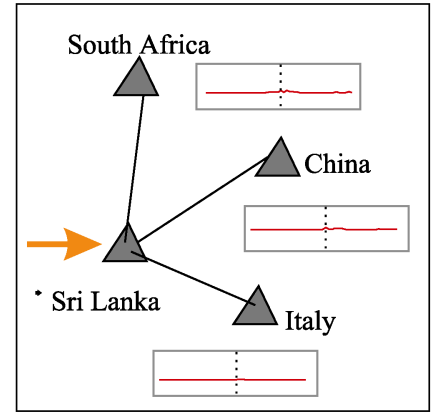

(d) Group 1 without clear trend changes

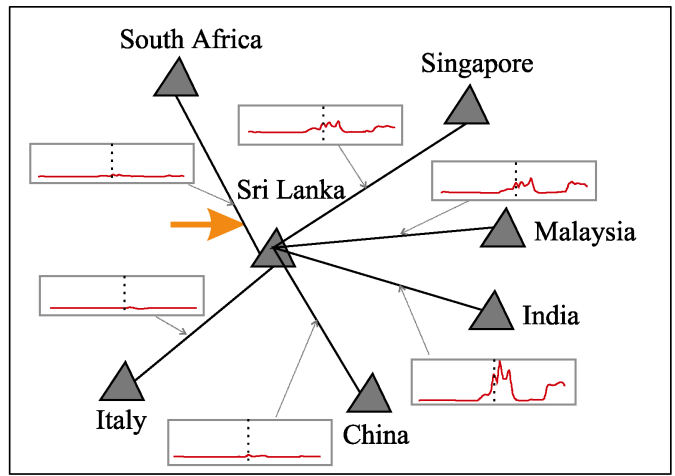

(b) Grouping the links with Sri Lanka

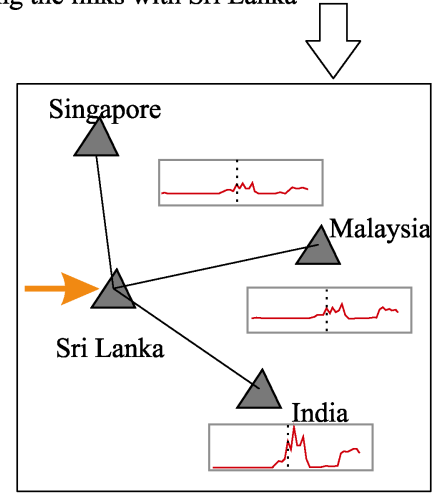

(e) Group 2 with trend changes

Figure 4 Grouping links with similar dynamics

\subsection{Evaluating possible affected countries via maritime network dynamics}

Evaluating the effects of international events on maritime networks is challenging because there is no direct evidence to prove a causal relationship. Therefore, in this study, we evaluate possible effects of international events using maritime network dynamics based on two perspectives: the directly affected countries and the indirect effect on linked countries. In addition, due to different types of vessels recorded in the AIS data, such as, tanker, container, and bulk, we created corresponding trend curves for each link in the maritime network.

This study considers a country as possibly affected by international events in a particular country if the links connected with this particular country have trend changes for at least one type of vessel. For example, in Figure 5, the curve for the link between India and Sri Lanka indicates a trend change after the international event. Therefore, India is one of the possible di-

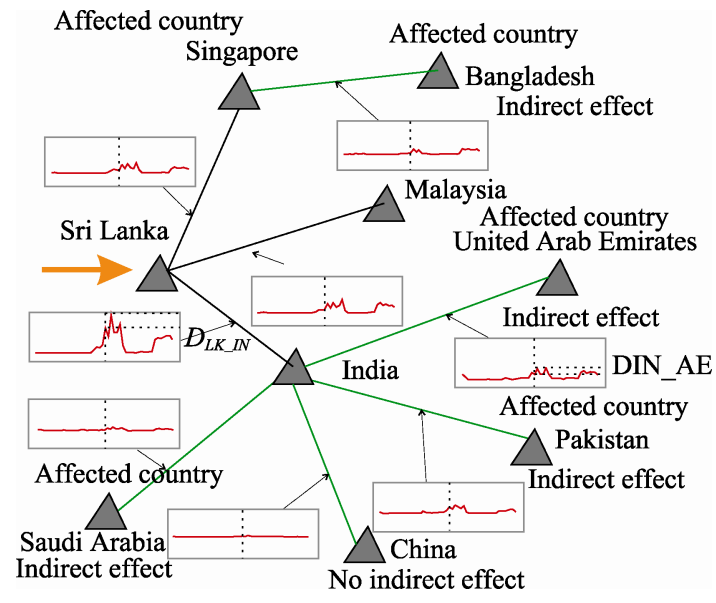

Figure 5 Evaluating countries potentially affected by an international event 
rectly affected countries.

If the next link to a country has similar trend changes for the same time period, the following country can be considered a potential indirectly affected country. For example, in Figure 5, the curve in the link between India and United Arab Emirates is similar to that between India and Sri Lanka, $D_{L K_{-} I N}>$ or $\left\langle D_{I N \_A E}\right.$, and the time $t$ for the peak point in this curve is approximately the same. Therefore, the United Arab Emirates is viewed as a possible indirectly affected country. We term this phenomenon the indirect effect. If there are no similar trends in the curves for other links between countries, these linked countries are considered unaffected countries, and there is no indirect effect.

Using this categorization, we can assess potentially affected countries for each type of vessel in the maritime network.

\section{Study area and results}

\subsection{Study area and dataset}

A global AIS dataset for the period between January 1, 2013 and December 31, 2016 (http://www.myships.com/myships/) was used to derive an Origin-Destination (OD) dataset for 20864 vessels and 3685 connecting ports worldwide. The data categories for each vessel are listed in Table 1. All AIS points for each vessel were simplified as a sequence of ports according to the records in the dataset.

Table 1 Data categories in the vessel OD dataset

\begin{tabular}{ll}
\hline \multicolumn{1}{c}{ Item } & \multicolumn{1}{c}{ Meaning } \\
\hline MMSI & Unique ID for the vessel \\
$\begin{array}{l}\text { Start time (Ship entering the port)/End time } \\
\text { (Ship leaving the port) }\end{array}$ & Second-level timestamp (e.g., 2015-06-10 01:16:58) \\
Port's location & Longitude and latitude of the port location \\
World_port_index_number & Index number for a port \\
Region_index & Index number for a region \\
Port_name & Name of the port \\
Wpi_country_code & Code for the port country \\
Vessel_type & Type of vessel (bulk / container / tanker) \\
Vessel_name & Name of the vessel \\
\hline
\end{tabular}

The global maritime network derived from AIS data for container, bulk, and tanker ships is shown in Figure 6. The high volumes of vessel voyages are highlighted individually in Figures $6 \mathrm{a}, 6 \mathrm{~b}$ and $6 \mathrm{c}$. These figures show clearly different connection patterns for the three types of vessels. The maritime networks generated for 2013, 2014, 2015, and 2016 are used to evaluate the effect of international events.

\subsection{Maritime network dynamics before and after events}

This section explores the maritime network dynamics before and after three selected typical international events: military conflicts between India and Pakistan in August, 2015 (Event A), lifting economic sanctions on Iran (Event B), and government elections in Sri Lanka 


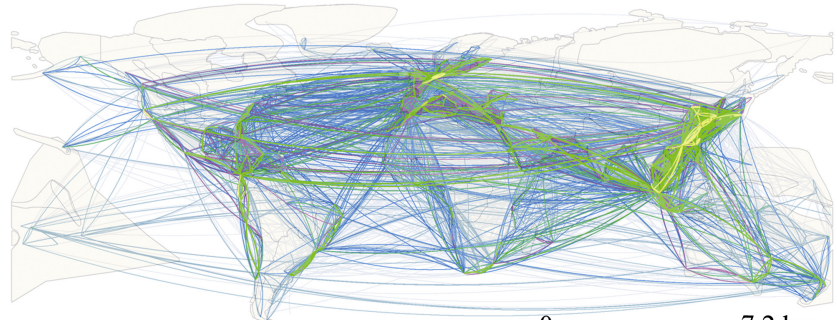

(a) Container

0 $7.2 \mathrm{~km}$

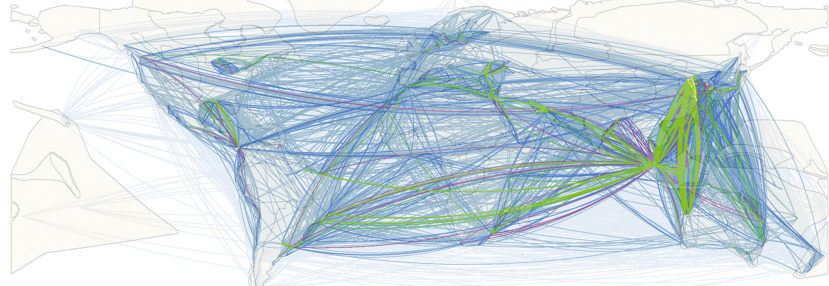

(b) Bulk

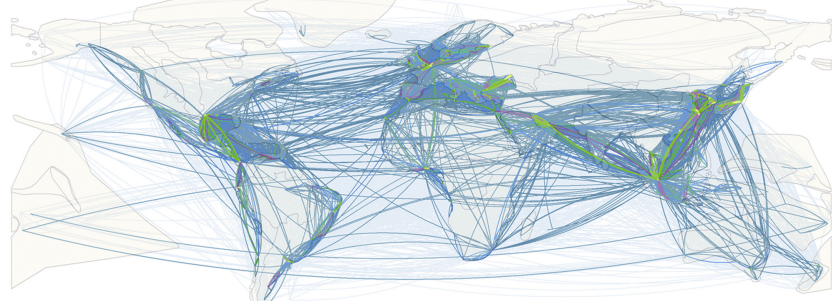

(c) Tanker
Legend

Geography_Regions

Linkage_intensity (>100 journeys)

_ Linkage_intensity (80-100 journeys)

__ Linkage_intensity (60-80 journeys)

__ Linkage_intensity (40-60 journeys)

__ Linkage_intensity (20-40 journeys) Linkage_intensity (6-20 journeys) Linkage_intensity (1-5 journeys)

Figure 6 Maritime network derived from AIS data for 2015

(Event C).

\subsubsection{Military conflict between India and Pakistan in August 2015 (Event A)}

A military conflict between India and Pakistan occurred in August 2015. In the border area between India and Pakistan, the Indian military fired on Pakistan, with the Pakistani military immediately fighting back. The fighting killed at least six Pakistani civilians and injured 46 people. This event was large enough to bring international scrutiny.

To evaluate the effects of this event, we clustered the top 20 maritime links connecting India based on tanker, bulk, and container ships, and then grouped them according to the proposed similarity measurement approach. Evaluating tanker shipping links, three groups were identified, a large fluctuation pattern (increase-slow down-slow down-increase-decrease) (Figure 7a-1), a small fluctuation pattern (small fluctuations-smooth increase) (Figure 7a-2), and a smooth pattern (Figure 7a-3). The United Arab Emirates (AE), Sri Lanka (LK), Pakistan (PK), and Singapore (SG) showed the large fluctuation pattern. In this pattern, there was a sharp decline in May 2015, and the tanker number in these countries decreased from August to December 2015. This pattern indicates that the event may have affected tanker shipping trade between India and these countries. Egypt (EG), Malaysia (MY), and Saudi Arabia (SA) showed a small fluctuation from 2013 to 2016. The fluctuation between January and August 2015 was greater than that after the military conflict, but the amplitude was small. Brazil (BR), China (CN), Indonesia (ID), Iraq (IQ), Iran (IR), Kenya (KE), Ku- 
wait (KW), Mozambique (MZ), Oman (OM), Qatar (QA), Tanzania (TZ), Venezuela (VE), and South Africa (ZA) showed a smooth pattern, indicating that this event had no effect on these countries for tanker ships.

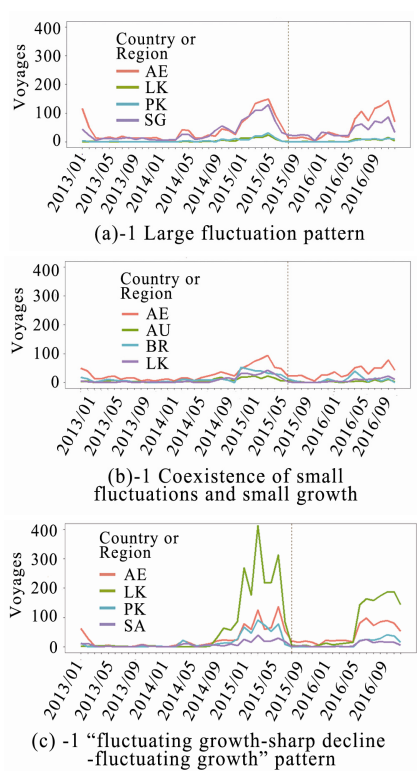

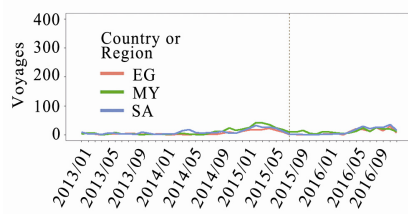

(a)-2 Small fluctuation pattern

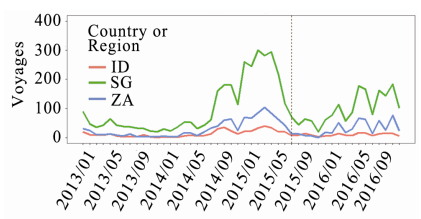

(b)-2 Large fluctuation

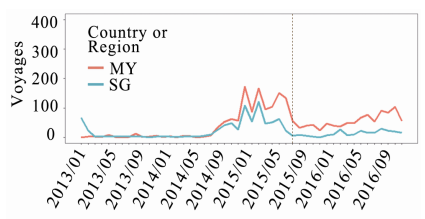

(c) -2 "fluctuating-gently increasing" pattern

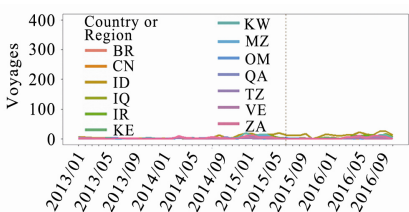

(a)-3 Smooth pattern

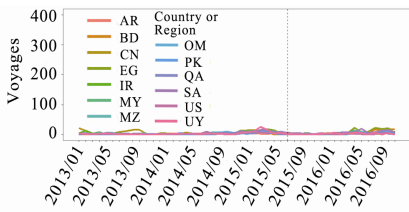

(b)-3 Overall smooth pattern

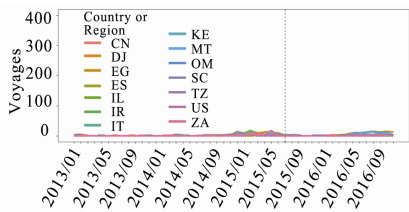

(c) -3 Overall gentle pattern

Figure 7 Grouped links based on similar dynamics for Event A, each panel shows international shipping trends with India via three types of ships: (a) tanker, (b) bulk, and (c) container. Columns 1-3 indicate the different groupings based on trade behavior before and after the event.

Three patterns emerged for bulk shipping: small fluctuations with small growth (Figure 7b-1), large fluctuations (Figure 7b-2), and an overall smooth pattern (Figure 7b-3). The combined small fluctuations and small growth appeared in United Arab Emirates (AE), Australia (AU), Brazil (BR), and Sri Lanka (LK). The first pattern shows that there was a small fluctuation before Event A, and a relatively gentle fluctuation after Event A, and then modest growth began in 2016. This pattern indicates that Event A had no clear effect on bulk ships between India and these countries. The second pattern appeared between India (IN) and Indonesia (ID), Singapore (SG), and South Africa (ZA). There was a large fluctuation from August 2014 to August 2015, and a slight fluctuation between August and December 2015 after Event A. This phenomenon indicates that Event A did not impact on bulk ships between India and these countries. The last pattern appeared in Argentina (AR), Bangladesh (BD), China (CN), Egypt (EG), Iran (IR), Malaysia (MY), Mozambique (MZ), Oman (OM), Pakistan (PK), Qatar (QA), Saudi Arabia (SA), the United States (US), and Uruguay (UY). Their changes were gentler than previous patterns, indicating that this event had no effect on bulk shipping with these countries.

Three patterns emerged in container shipping: "fluctuating growth-sharp decline-fluctuating growth" (Figure 7c-1), "fluctuating-gently increasing" (Figure 7c-2), and an overall gentle pattern (Figure 7c-3). The first pattern appeared in the shipping with the United Arab Emirates (AE), Sri Lanka (LK), Pakistan (PK), and Saudi Arabia (SA). There was volatile growth from August 2014 to June 2015, a sharp decline from June 2015 to August, followed 
by fluctuating growth from September 2015 to May 2016. The second pattern appeared in Malaysia (MY) and Singapore (SG). The main fluctuations occurred from August 2014 to July 2015, and were followed by steady growth. The third pattern, no trends, appeared in shipping with China (CN), Djibouti (DJ), Egypt (EG), Spain (ES), Israel (IL), Iran (IR), Italy (IT), Kenya (KE), Malta (MT), Oman (OM), Seychelles (SC), Tanzania (TZ), the United States (US), and South Africa (ZA).

In summary, maritime network dynamics between India and other countries show clear differences before and after Event A. There were large fluctuations in the network dynamics for tanker, bulk, and container ships between India and the United Arab Emirates (AE), Sri Lanka (LK), and Singapore (SG). Furthermore, network dynamics for container and tanker ships between India (IN) and Pakistan (PK), Saudi Arabia (SA), and Malaysia (MY) also showed large fluctuations. The network dynamics for bulk ships between India (IN) and Australia (AU), Indonesia (ID), South Africa (ZA), Brazil (BR) showed a clear effect. The link between India (IN) and Egypt (EG) showed large fluctuations only for tanker ships.

This study also explored the maritime time network dynamics before and after Events B and C. Similar analyses were performed, and our results, i.e., the shipping trends are provided as follows.

\subsubsection{Economic sanction on Iran (Event B)}

On July 16, 2015, the United States (US), the United Kingdom (UK), France (FR), Russia (RU), China (CN), Germany (DE), and Iran (IR) reached comprehensive agreement on the issue of Iranian nuclear materials. Subsequently, the Western countries began to lift economic sanctions against Iran. Investigating the effect of this event on global maritime network dynamics is important because Iran is an important member of the Organization of Petroleum Exporting Countries (OPEC).

Figure 8a illustrates the seasonal fluctuation pattern of bulk shipping for the United Arab Emirates (AE), China (CN), Indonesia (ID), India (IN), Iraq (IQ), Kuwait (KW), Oman (OM), Pakistan (PK), Qatar (QA), Saudi Arabia (SA), and South Africa (ZA) linked with Iran. There were clear seasonal fluctuations between January 2013 and July 2015, which continued after Event B. However, this trend did not show significant changes from August 2015 to December 2016. This indicates that Event B did not affect the bulk trade between these countries.

Figure $8 \mathrm{~b}$ shows the typical container shipping patterns with Iran before and after Event $\mathrm{B}$ for the United Arab Emirates (AE), Bahrain (BH), Djibouti (DJ), Hong Kong (China), India (IN), Kenya (KE), Kuwait (KW), Sri Lanka (LK), Pakistan (PK), and Saudi Arabia (SA). Container shipping had a fluctuating, but increasing from January to July 2015 (before Event B). From August to September 2015 there was a slight decline and then continued fluctuations, indicating that the lifted economic sanctions did not immediately promote Iran's container shipping network with these countries (regions).

Figures $8 \mathrm{c}-1$ and $8 \mathrm{c}-2$ illustrate the tanker shipping before and after Event $\mathrm{B}$ between Iran and linked countries (regions). Figure 8c-1 only includes the United Arab Emirates, where there was a growth trend from January to July 2015. After Event B, the trend continued to increase, but with large fluctuations; there were also clear seasonal effects, with decreases every 10-12 months. The number of tanker voyages clearly increased after this event, so this event played a role in promoting the tanker network between these two countries (regions). 
Figure 8c-2 includes Bahrain (BH), China (CN), Egypt (EG), Hong Kong (China), Indonesia (ID), India (IN), Iraq (IQ), Japan (JP), Korea (KR), Kuwait (KW), Malaysia (MY), Oman (OM), Pakistan (PK), Qatar (QA), Saudi Arabia (SA), Singapore (SG), Syria (SY), Turkey (TR), and Taiwan (China). Before and after this event, the tanker maintained the same trend, indicating that there was no significant impact on Iran's tanker maritime network with those countries (regions).

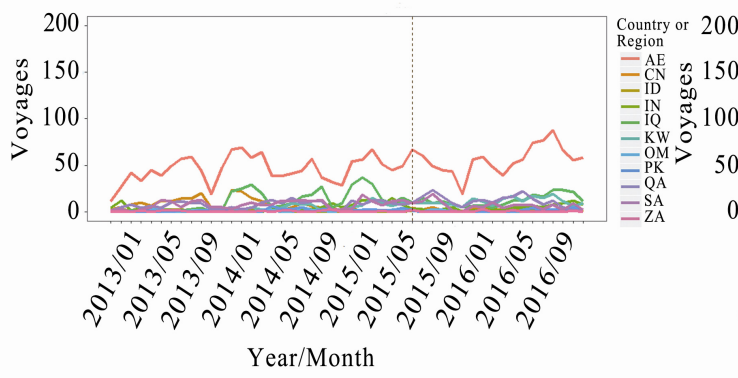

(a) Seasonal fluctuation pattern of bulk

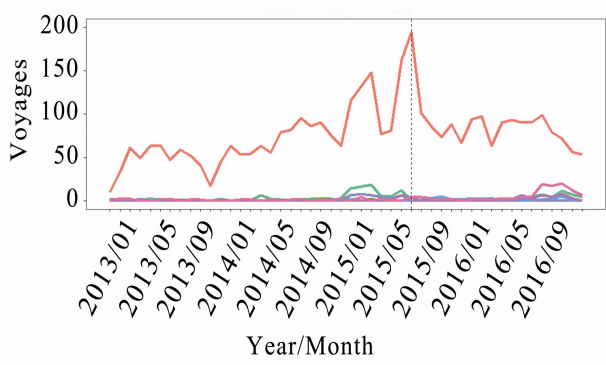

(b) Fluctuation pattern of container

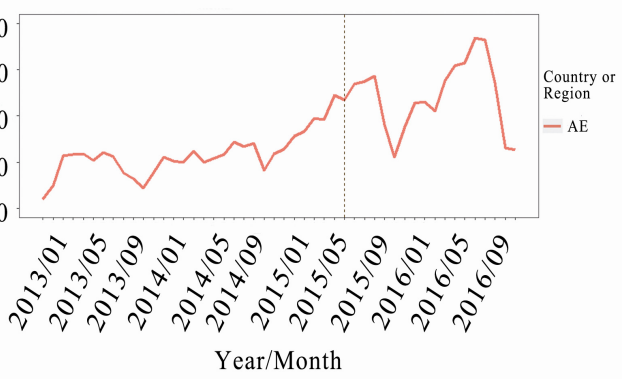

(c)-1 An obvious pattern of tanker

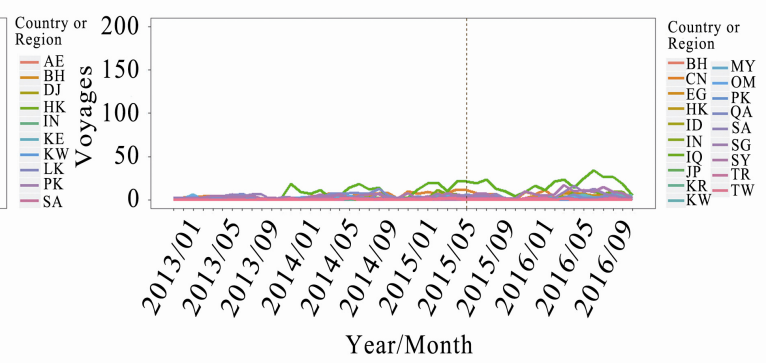

(c)-2 Other small fluctuation pattern of tanker

Figure 8 Variations in the number of (a) bulk, (b) container, and (c)-1 and (c)-2 tanker shipping voyages between Iran and linked countries (regions) before and after Event B

In summary, lifting Iran's economic sanctions had no obvious effect on Iran's bulk, container, and tanker shipping network with other countries (); one of the few exceptions was the increase in tanker shipping between Iran and the United Arab Emirates.

\subsubsection{Government election in Sri Lanka (Event C)}

In the presidential election of 2015 in Sri Lanka, Rajapaksa was defeated and Sirisena was elected as the new President. In February 2015, President Sirisena visited India; subsequently, on March 5 of the same year, the Sri Lankan government decided to halt the construction of the Colombo Port temporarily, an investment location for Chinese enterprises. This event was at the intersection of politics, economics, and maritime activity, so investigating the effect of this event on global maritime network dynamics is important.

Figure 9 illustrates the changes in bulk, container, and tanker shipping for Sri Lanka before and after Event C. Figures 9a and 9b show no clear changes in bulk and tanker shipping between Sri Lanka and other countries. However, clear changes appeared in container shipping with India (IN), Malaysia (MY), and Singapore (SG). In Figures 9c-1 and 9c-2, an obvious overall increasing trend in container shipping occurred from March to August 2015, followed by a decrease to a low level between August 2015 and May 2016, below that of August 2014. This observation indicates that the event potentially played a role in promoting container shipping connections between Sri Lanka (LK) and India (IN), Malaysia (MY), and 
Singapore (SG).

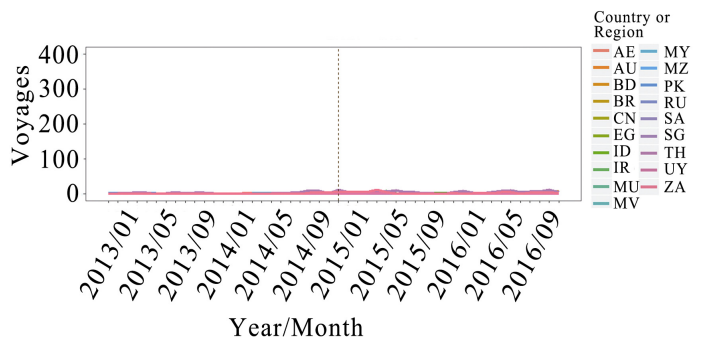

(a) No obvious change of bulk

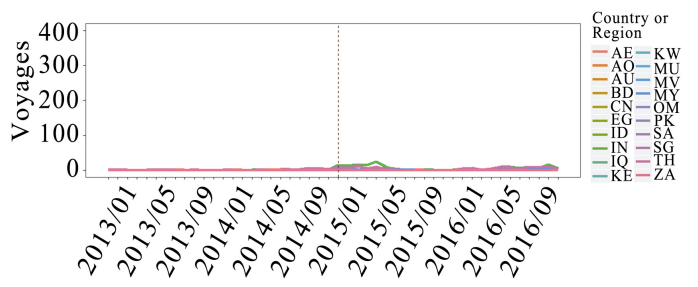

Year/Month

(b) No obvious change of tanker

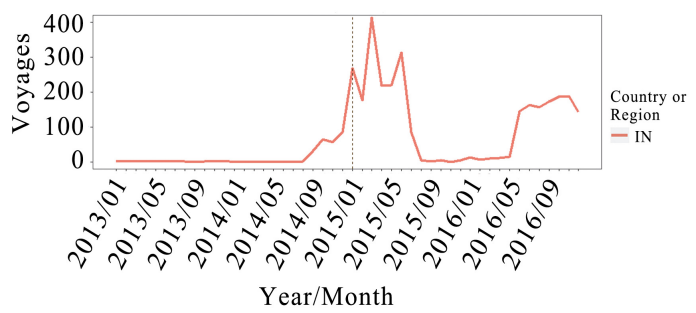

(c)-1 Obvious change of container with India

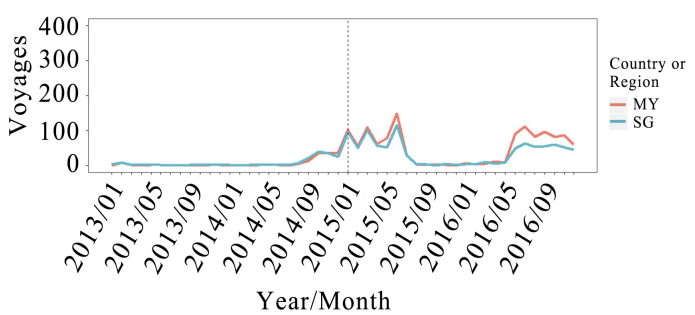

(c)-2 Obvious change of container with Malaysia and Singapore

Figure 9 Variations in the number of bulk, container, and tanker shipping voyages before and after Event $\mathrm{C}$ between Sri Lanka and countries linked by shipping, (a) bulk shipping linked with major countries and regions, (b) tanker shipping linked with major countries and regions, (c)-1 container shipping linked with India, and (c)-2 container shipping linked with Malaysia and Singapore

\subsection{Assessing possible indirect effects}

We also evaluated possible indirect effects by exploring similar patterns in adjacent links in the maritime networks using the proposed method.

Figure 10 illustrates the derived maritime network between countries with variations in network dynamics or similar fluctuations before and after Event $\mathrm{A}$. The figure is used to demonstrate the type of vessel affected by Event A. The figure shows India is the first country used to explore the maritime network dynamics, although Pakistan was also involved in this event. South Africa, Malaysia, Indonesia, Sri Lanka, Singapore, Australia, Saudi Arabia, Egypt, the United Arab Emirates, and Brazil are linked to India (orange ovals, termed the direct connected link) and show fluctuations in vessel types. The countries with green and orange ovals share similar network dynamics, termed the indirect connected links. From the figure, several observations can be made:

i) The United Arab Emirates, Singapore, Saudi Arabia, and Malaysia are linked to some indirect affected countries with similar fluctuation dynamics as their links with India for container shipping. Also, Egypt and Brazil are linked to some indirect affected countries with similar fluctuation dynamics as their link with India for tanker shipping. This situation is evidence of a possible indirect effect for these vessel types. Figure 11 shows the spatial distribution of countries potentially affected by Event A.

ii) Australia, South Africa, and Indonesia did not have indirect connected links, i.e., their linkages to other countries had significantly different dynamics patterns from their links with India. Malaysia, Singapore, the United Arab Emirates, and Saudi Arabia only had indirect connected links for containers, and did not have similar fluctuation dynamics for bulk and 
tanker shipping. This phenomenon indicates that it is possible for these countries to show an indirect effect only for container shipping.

Based on countries potentially affected by Event A in Figure 10, we analyzed the observed changes in network dynamics and found that after Event $A$ the average container shipping voyages between India and United Arab Emirates, Sri Lanka, Pakistan, Saudi Arabia, Malaysia, and Singapore declined by $79.7 \%, 97.8 \%, 99.5 \%, 95.2 \%, 69.1 \%$, and $92.0 \%$, respectively. The average tanker shipping voyages between India and United Arab Emirates, Sri Lanka, Pakistan, Singapore, Egypt, Malaysia, Saudi Arabia declined by 85.1\%, 95.7\%, $99.0 \%, 73.9 \%, 93.8 \%, 69.1 \%$, and $94.9 \%$, respectively. The average bulk shipping between India and United Arab Emirates, Australia, Sri Lanka, Indonesia, Singapore, South Africa, and Brazil declined by $69.3 \%, 83.9 \%, 97.1 \%, 72.1 \%, 77.2 \%, 86.1 \%$, and $80.1 \%$, respectively.

Table 2 provides details for the derived maritime network between countries that showed

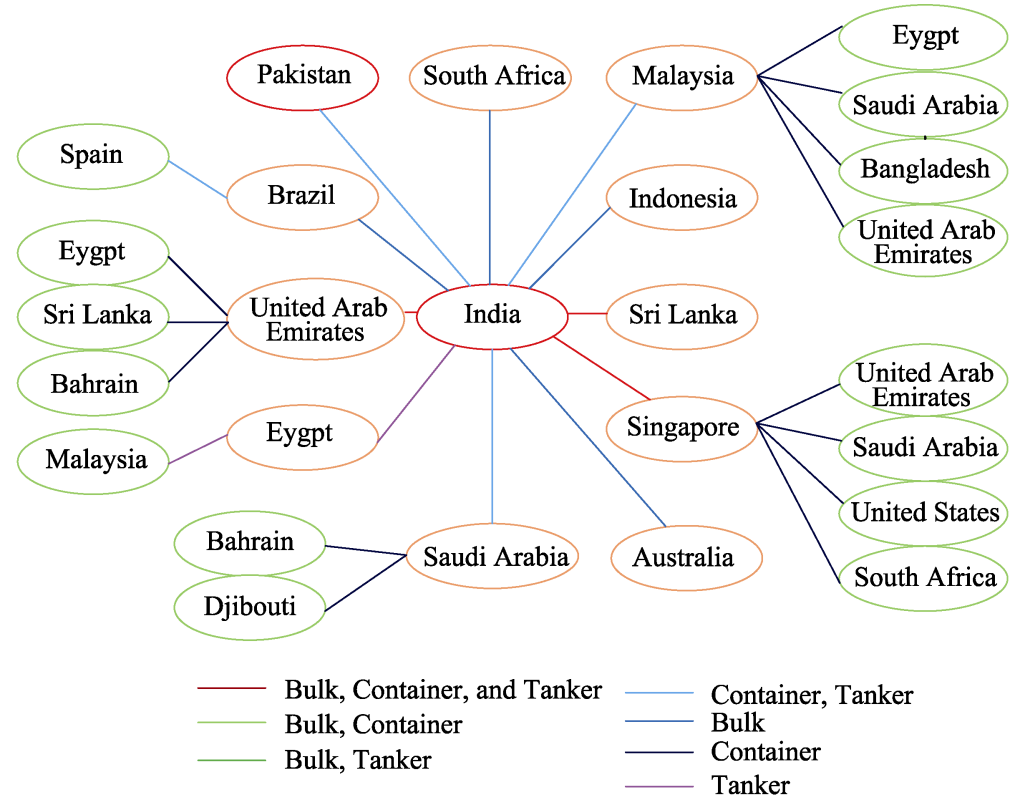

Figure 10 The countries possibly affected by Event A and their shipping linkages in terms of different types of shipping

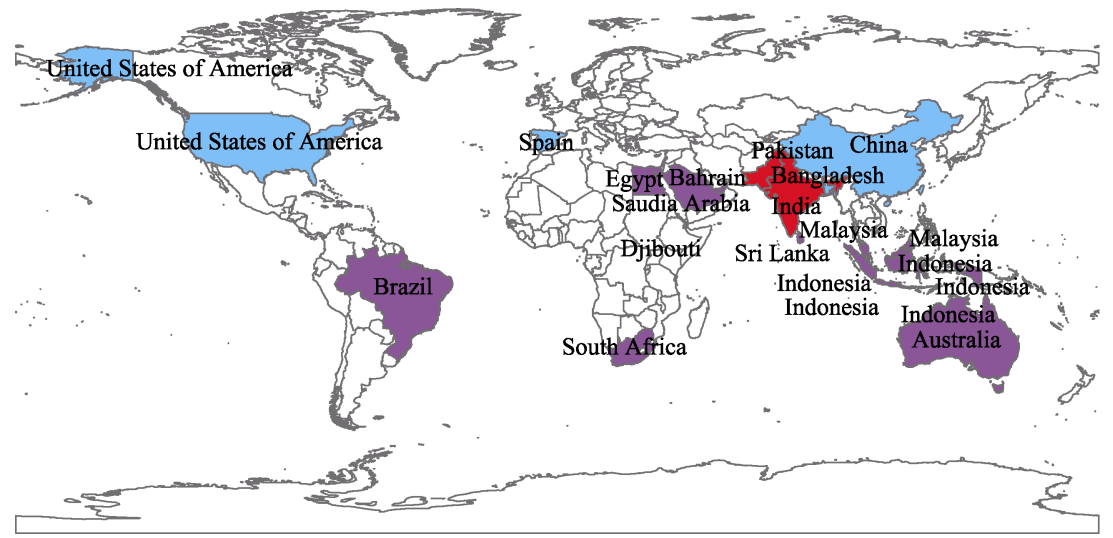

Figure 11 Spatial distribution of countries possibly affected by Event A 
variations in network dynamics or similar fluctuations before and after Event B. Only the United Arab Emirates showed clear fluctuations in shipping with Iran, and only for tanker shipping. The actual changes in the network dynamics indicate that tanker shipping between Iran and the United Arab Emirates increased by 51\%, i.e., the average voyages increased from 59.806 to 121.176 after lifting economic sanctions on Iran. In addition, the link between the United Arab Emirates and Indonesia had similar fluctuation dynamics (0.473) to that between Iran and the United Arab Emirates.

Table 2 Countries potentially affected by Event B

\begin{tabular}{|c|c|c|c|c|c|c|c|}
\hline Link & $\begin{array}{l}\text { Highest } \\
\text { number of } \\
\text { voyages } \\
\text { and time } \\
\text { period }\end{array}$ & $\begin{array}{c}\text { Lowest } \\
\text { number of } \\
\text { voyages and } \\
\text { time period }\end{array}$ & $\begin{array}{l}\text { Average } \\
\text { voyages } \\
\text { before } \\
\text { Event B }\end{array}$ & $\begin{array}{c}\text { Average } \\
\text { voyages } \\
\text { after } \\
\text { Event B }\end{array}$ & $\begin{array}{l}\text { Minimum } \\
\text { crossing } \\
\text { area after } \\
\text { standardi- } \\
\text { zation }\end{array}$ & $\begin{array}{l}\text { Time pe- } \\
\text { riod for the } \\
\text { same trend } \\
\text { after stan- } \\
\text { dardi- } \\
\text { zation }\end{array}$ & $\begin{array}{c}\text { Similarity of } \\
\text { time-varying } \\
\text { changes } \\
\text { (1/journeys) }\end{array}$ \\
\hline $\begin{array}{c}\text { Iran-United } \\
\text { Arab Emirates }\end{array}$ & $\begin{array}{c}143 \\
(2015-10)\end{array}$ & $\begin{array}{c}64 \\
(2015-01)\end{array}$ & 59.806 & 121.176 & \multirow[b]{2}{*}{0.353} & \multirow[b]{2}{*}{0.167} & \multirow[b]{2}{*}{0.473} \\
\hline $\begin{array}{c}\text { United Arab } \\
\text { Emirates- } \\
\text { Indonesia }\end{array}$ & $\begin{array}{c}17 \\
(2015-10)\end{array}$ & $\begin{array}{c}3 \\
(2015-02)\end{array}$ & 5.871 & 12.294 & & & \\
\hline
\end{tabular}

Table 3 provides details of the derived maritime network between countries that have variations in network dynamics or similar fluctuations before and after Event C. Only India, Malaysia, and Singapore showed clear fluctuations in shipping with Sri Lanka. The actual changes in network dynamics show that the container shipping between Sri Lanka and Singapore, Malaysia, and India increased by $73.6 \%$, 78.9\%, and $85.8 \%$, respectively, after Event $\mathrm{C}$; the average increases in voyages are provided in Table 3. Similar fluctuation dynamics between the direct connected links and indirect connected links are found for the United Arab Emirates (0.811), Saudi Arabia (0.489), Pakistan (0.741), and Bangladesh (0762) for container shipping. All adjacent connected links with Malaysia had different fluctuation dynamics from the link between India and Malaysia, so they did not show a possible indirect effect.

Table 3 Countries potentially affected by Event C

\begin{tabular}{|c|c|c|c|c|c|c|c|}
\hline Link & $\begin{array}{l}\text { Highest num- } \\
\text { ber of voyages } \\
\text { and time } \\
\text { period }\end{array}$ & $\begin{array}{c}\text { Lowest } \\
\text { number of } \\
\text { voyages and } \\
\text { time period }\end{array}$ & $\begin{array}{c}\text { Average } \\
\text { voyages } \\
\text { before } \\
\text { Event } \\
\text { C }\end{array}$ & $\begin{array}{c}\text { Average } \\
\text { voyages } \\
\text { after } \\
\text { Event } \\
\text { C }\end{array}$ & $\begin{array}{l}\text { Minimum } \\
\text { crossing } \\
\text { area after } \\
\text { standardi- } \\
\text { zation }\end{array}$ & $\begin{array}{l}\text { Time } \\
\text { period of } \\
\text { the same } \\
\text { trend after } \\
\text { standardi- } \\
\text { zation }\end{array}$ & $\begin{array}{c}\text { Similarity } \\
\text { of time- } \\
\text { varying } \\
\text { changes } \\
\text { (1/journeys) }\end{array}$ \\
\hline Sri Lanka-India & $412(2015-03)$ & 0 (2014-07) & 34.286 & 241.286 & & & \\
\hline $\begin{array}{l}\text { India-United } \\
\text { Arab Emirates }\end{array}$ & $136(2015-06)$ & $0(2014-07)$ & 15.571 & 85.857 & 0.444 & 0.361 & 0.811 \\
\hline India-Saudi Arabia & $39(2015-03)$ & $0(2014-06)$ & 4.429 & 23.857 & 0.530 & 0.259 & 0.489 \\
\hline India-Pakistan & $91(2015-03)$ & $3(2014-06)$ & 10.286 & 59.571 & 0.250 & 0.185 & 0.741 \\
\hline Sri Lanka-Singapore & $114(2015-06)$ & 1 (2014-07) & 18.571 & 70.429 & \multirow{2}{*}{0.413} & \multirow{2}{*}{0.315} & \multirow{2}{*}{0.762} \\
\hline Singapore-Bangladesh & $50(2015-03)$ & $1(2014-07)$ & 8.833 & 23.714 & & & \\
\hline Sri Lanka-Malaysia & $148(2015-06)$ & $0(2014-07)$ & 17.571 & 83.143 & & & \\
\hline
\end{tabular}




\section{Conclusions and future work}

This study proposed an AIS-based approach to explore maritime network dynamics before and after international events. This approach provides a mechanism for comparing time-series variations in maritime networks driven by international events and identifying connected links with similar dynamics close in time to the events. The results show that container, tanker, bulk shipping between India and other countries all declined by more than 69\% after the military conflict between India and Pakistan in August 2015. Tanker shipping between Iran and the United Arab Emirates increased by 51\% after the lifting of economic sanctions on Iran, and container shipping between Sri Lanka and Singapore, Malaysia, and India increased by more than 74\% after the government election in Sri Lanka. These case studies demonstrate the feasibility and capability of this approach in understanding maritime network dynamics.

Although this work is an initial step for investigating the effect of international events on spatiotemporal dynamics of maritime network, it could be helpful for developing national strategies in combination with economics, customs, geography, and political information. In the future, this approach could be improved by integrating such comprehensive information. Furthermore, introducing and understanding the mechanisms driving structural and regional dynamics in global maritime networks, analyzing the industries affected by events, and linking them with the corresponding types of maritime network will be promising.

\section{References}

Akhtar M J, Utne I B, 2014. Human fatigue's effect on the risk of maritime groundings: A Bayesian network modeling approach. Safety Science, 62: 427-440.

Angeloudis P, Greco L, Bell M G, 2015. Strategic maritime container transport design in Oligopolistic markets. Transportation Research Procedia, 9: 269-282.

Arora1 P, Deepali D, Varshney S, 2016. Analysis of K-means and K-medoids algorithm for big data. Procedia Computer Science, 78: 507-512

Bezgodov A, Esin D, 2014. Complex network modeling for maritime search and rescue operations. Procedia Computer Science, 29: 2325-2335.

Borgwardt S, Brieden A, Gritzmann P, 2017. An LP-based K-means algorithm for balancing weighted point sets. European Journal of Operational Research, 263: 349-355.

Box G E, Jenkins G M, Reinsel G C et al., 1976. Time Series Analysis: Forecasting and Control. San Francisco: Holden-Day.

Campana I, Angeletti D, Crosti R et al., 2017. Seasonal characterisation of maritime traffic and the relationship with Cetacean presence in the Western Mediterranean Sea. Marine Pollution Bulletin, 115: 282-291.

Castaldo F, Palmieri F A, Regazzoni C, 2015. Application of Bayesian techniques to behavior analysis in maritime environments. In: Advances in Neural Networks: Computational and Theoretical Issues. Switzerland: Springer, 175-183.

Cleveland W S, Devlin S J, Grosse E, 1988. Regression by local fitting: Methods, properties, and computational algorithms. Journal of Econometrics, 37(1): 87-114.

Davarzani H, Fahimnia B, Bell M et al., 2016. Greening ports and maritime logistics: A review. Transportation Research Part D, 48: 473-487.

Dinwoodie J, Tuck S, Rigot-Müller P, 2013. Maritime oil freight flows to 2050: Delphi perceptions of maritime specialists. Energy Policy, 63: 553-561.

Doloreux D, Shearmur R, Figueiredo D, 2016. Québec' coastal maritime cluster: Its impact on regional economic development, 2001-2011. Marine Policy, 71: 201-209.

Ducruet C, 2013. Network diversity and maritime flows. Journal of Transport Geography, 30: 77-88. 
Ducruet C, 2016. Maritime Network Spatial Structure and Time Dynamics. New York: Routledge.

Ducruet C, 2017. Multilayer dynamics of complex spatial networks: The case of global maritime flows (1977-2008). Journal of Transport Geography, 60: 47-58.

Ducruet C, Lee S W, Ng A K, 2010. Centrality and vulnerability in liner shipping networks: Revisiting the Northeast Asian port hierarchy. Maritime Policy Management, 37(1): 17-36.

Ducruet C, Lee S W, Roussin S, 2009. Local strength and global weakness: A maritime network perspective on South Korea as Northeast Asia's logistics hub. International Journal of Maritime Affairs and Fisheries, 1(1): $32-50$.

Ducruet C, Notteboom T, 2012. The worldwide maritime network of container shipping: Spatial structure and regional dynamics. Global Networks, 12(3): 395-423.

Fahmiasari H, Parikesit D, 2017. Container shipping network efficiency comparison in Indonesia: Nusantara Pendulum and Sea Tollway. The Asian Journal of Shipping and Logistics, 33(2): 79-84.

Fiorini M, Capata A, Bloisi D D, 2016. AIS data visualization for maritime spatial planning (MSP). International Journal of e-Navigation and Maritime Economy, 5: 45-60.

Fremont A, 2007. Global maritime networks: The case of Maersk. Journal of Transport Geography, 15: 431-442.

Fugazza M, Hoffmann J, 2017. Liner shipping connectivity as determinant of trade. Journal of Shipping and Trade, 2(1): 1 .

Gagatsi E, Giannopoulos G, Aifantopoulou G et al., 2017. Stakeholders-based multi-criteria policy analysis in maritime transport: From theory to practice. Transportation Research Procedia, 22: 655-664.

Guerrero D, Rodrigue J P, 2014. The waves of containerization: Shifts in global maritime transportation. Journal of Transport Geography, 34: 151-164.

Hänninen M, Banda O A V, Kujala P, 2014. Bayesian network model of maritime safety management. Expert Systems with Applications, 41: 7837-7846.

$\mathrm{Hu}$ Y H, Zhu D L, 2009. Empirical analysis of the worldwide maritime transportation network. Physica A, 388: 2061-2071.

Høye G K, Eriksen T, Meland B J et al., 2008. Space-based AIS for global maritime traffic monitoring. Acta Astronautica, 62: 240-245.

Jiang J, Lee L H, Chew E P et al., 2015. Port connectivity study: An analysis framework from a global container liner shipping network perspective. Transportation Research Part E, 73: 47-64.

Karsten C V, Brouer B D, Pisinger D, 2017. Competitive liner shipping network design. Computers \& Operations Research, 87: 125-136.

Kim J Y, 2014. Port user typology and representations of port choice behavior: A Q-methodological study. Maritime Economics \& Logistics, 16: 165-187.

King G, Zeng L C, 2001. Explaining rare events in international relations. International Organization, 55(3): $693-715$.

Knappett C, Evans T, Rivers R, 2008. Modelling maritime interaction in the Aegean Bronze Age. Antiquity, 82: 1009-1024.

Kumar K M, Reddy A R M, 2017. An efficient K-means clustering filtering algorithm using density based initial cluster centers. Information Sciences, 418: 286-301.

Lam J S L, Yap W Y, 2011. Dynamics of liner shipping network and port connectivity in supply chain systems: Analysis on East Asia. Journal of Transport Geography, 19(6): 1272-1281.

Laxe F G, Seoane M J F, Montes C P, 2012. Maritime degree, centrality and vulnerability: Port hierarchies and emerging areas in containerized transport (2008-2010). Journal of Transport Geography, 24: 33-44.

Lee H, Boile M, Theofanis S et al., 2012. Modeling the oligopolistic and competitive behavior of carriers in maritime freight transportation networks. Procedia - Social and Behavioral Sciences, 54: 1080-1094.

Lee H, Moile M, Theofanis S et al., 2014. Game theoretical models of the cooperative carrier behavior. KSCE Journal of Civil Engineering, 18(5): 1528-1538.

Lei P R, 2016. A framework for anomaly detection in maritime trajectory behavior. Knowledge and Information Systems, 47(1): 189-214.

Li K X, Yin J, Bang H S et al., 2014a. Bayesian network with quantitative input for maritime risk analysis. Transportmetrica A: Transport Science, 10(2): 89-118.

Li Z F, Li H, Xu M Q et al., 2014b. Comparison research on reachability of the global shipping network. Journal of Dalian Maritime University, 40(1): 101-104. (in Chinese) 
Li Z F, Shi Y L, Xu M Q et al., 2016. Heterogeneity of global shipping network. China Science Paper, 11(7): 793-797. (in Chinese)

Liu C L, Wang J Q, Zhang H, 2017. Spatial heterogeneity of ports in the global maritime network detected by weighted ego network analysis. Maritime Policy \& Management, 1-16.

Liu C J, Hu Z H, 2017. Hierarchy system research about the maritime silk road shipping network. Economic Geography, 37(7): 26-32. (in Chinese)

Lloyd S P, 1982. Least squares quantization in PCM. IEEE Transactions on Information Theory, 28(2): $129-137$.

MacKinlay A C, 1997. Event studies in economics and finance. Journal of Economic Literature, 35(1): 13-39.

MacQueen J B, 1967. Some methods of classification and analysis of multivariate observations. In: Proceedings of the Fifth Berkeley Symposium on Mathematical Statistics and Probability, 281-297.

Mohamed-Chérif F, Ducruet C, 2016. Regional integration and maritime connectivity across the Maghreb seaport system. Journal of Transport Geography, 51: 280-293.

Peng P, Cheng S F, Liu X L et al., 2017. The robustness evaluation of global maritime transportation networks. Acta Geographica Sinica, 72(12): 2241-2251. (in Chinese)

Rodrigue J P, 2017. The governance of intermediacy: The insertion of Panama in the global liner shipping network. Research in Transportation Business and Management, 22: 21-26.

Rodrigue J P, Browne M, 2002. International Maritime Freight Movements and Logistics. Transport Geographies: An Introduction, 156-178.

Schinas O, von Westarp A G, 2017. Assessing the impact of the maritime silk road. Journal of Ocean Engineering and Science, 2(3): 186-195.

Silva V M D, 2013. The dynamics of the collaborative maritime transportation. Proceedings Volumes, 46(24): 79-86.

Song D P, Zhang J, Carter J et al., 2005. On cost efficiency of the global container shipping network, Maritime Policy and Management, 32(1): 15-30.

Song D W, Lee P T W, 2009. Maritime logistics in the global supply chain. International Journal of Logistics Research and Applications: A Leading Journal of Supply Chain Management, 12(2): 83-84.

Stopford M, 2009. Maritime Economics. London and New York: Routledge.

Tai H H, Hwang C C, 2005. Analysis of hub port choice for container trunk lines in East Asia. Journal of the Eastern Asia Society for Transportation Studies, 6: 907-919.

Talley W K, Ng M W, 2013. Maritime transport chain choice by carriers, ports and shippers. International Journal of Production Economics, 142: 311-316.

Tian W, Deng S G, Wu P J et al., 2007. Analysis of complexity in global shipping network. Journal-Dalian University of Technology, 47(4): 605. (in Chinese)

van Leeuwen J, 2015. The regionalization of maritime governance: Towards a polycentric governance system for sustainable shipping in the European Union. Ocean \& Coastal Management, 117: 23-31.

Viederyte R, 2013. Maritime cluster organizations: Enhancing role of maritime industry development. Procedia: Social and Behavioral Sciences, 81: 624-631.

Viljoen N M, Joubert J W, 2016. The vulnerability of the global container shipping network to targeted link disruption. Physica A, 462: 396-409.

Wang C J, Wang J E, 2011. Spatial pattern of the global shipping network and its hub-and-spoke system. Research in Transportation Economics, 32(1): 54-63.

Wang N, Dong L L, Wu N et al., 2016. The change of global container shipping network vulnerability under intentional attack. Acta Geographica Sinica, 71(2): 293-303. (in Chinese)

Wu D, Wang N, Wu N et al., 2017. The impact of main channel interruption on vulnerability of container shipping network and China container shipping. Geographical Research, 36(4): 719-730. (in Chinese)

Xu M Q, Li Z F, Shi Y L et al., 2015a. Evolution of regional inequality in the global shipping network. Journal of Transport Geography, 44: 1-12.

Xu M Q, Li Z F, Shi Y L et al., 2015b. Spatial linkage of global container shipping network. Journal of Shanghai Maritime University, 36(3): 6-12. (in Chinese)

Yu H C, Fang Z X, Peng G J et al., 2017. Revealing the linkage network dynamic structures of Chinese maritime ports through automatic information system data. Sustainability, 9(10): 1913.

Zeng Z B, Yang Z, 2002. Dynamic programming of port position and scale in the hierarchized container ports network. Maritime Policy and Management, 29(2): 163-177. 